\title{
O CONCEITO DE RESSONÂNCIA NO PROCESSO DE FORMAÇÃO DO TERAPEUTA: DESCOBRINDO POTENCIALIDADES E LIMITAÇÕES NA PRÁTICA TERAPÊUTICA
}

ntre os anos 60 e finais dos 80, no ocidente, começaram a se tornar visíveis alternativas aos modelos existentes dominantes com os quais se pensava o mundo e os modos de viver nessa época. Nos Estados Unidos, em dois campos acadêmicos diferentes - a psicologia social e as teorias de comunicação - começaram a ser produzidas propostas centradas na realidade construída socialmente, ou seja, relacionalmente.

Até os finais dos anos 70 o objeto de estudo era o sistema "família", sendo o terapeuta um observador externo, com poder de avaliar, diagnosticar e traçar os objetivos para a terapia. Poucos se interessavam pelo "sistema terapêutico" - mais adiante renomeado por Harry Goolishian como "sistema determinado pelo problema”.

A partir dos anos 80 o movimento construtivista foi absorvido por boa parte da comunidade dos terapeutas de família, através das obras de Paul Watzlawick, Ernst von Glasersfeld, Heinz von Foerster, Humberto Maturana e Francisco Varela. Alguns anos mais tarde surgia o movimento do Construcionismo Social, sustentado e desenvolvido simultaneamente em vários países, e que propunha substituir a metáfora cibernético/sistêmica pela metáfora pós-moderna e antropológica. Os nomes de Kenneth Gergen na psicologia social e os de Barnett Pearce, Vernon Cronen e Stephen Littlejohn nos estudos sobre comunicação humana foram acompanhados pelos trabalhos de Tomas Ibañez Gracia na Espanha, Pablo Fernandez Cristieb no México, Esther Wiesenfeld na Venezuela e Saul Fuks na Argentina, que trabalharam essas ideias nos campos da psicologia social comunitária e no da psicologia da saúde.

Neste contexto efervescente nomes importantes trouxeram contribuições valiosas para a terapia de família. Aqui entra nosso amigo Mony Elkaïm que, entre outros aportes criativos, criou o conceito de "ressonância" aplicado à terapia.

Numa linha menos radical do Construcionismo Social, onde tudo é relacional, e a experiência que temos do Eu é uma experiência de subjetividade e as narrativas são relacionalmente construídas, dando espaço a um sentimento de identidade pessoal, a ressonância é uma metáfora para falar de uma forma de conexão com os outros.

Teoricamente a ressonância se inspira na noção de transversalidade de Felix Guattari e no isomorfismo da teoria sistêmica. A transversalidade é um conceito/dimensão que pretende superar dois impasses: o de uma verticalidade pura (ou seja, o de uma hierarquização entre pontos e saberes distintos) e de uma simples horizontalidade (ou seja, de conexões somente entre áreas afins e semelhantes). Ela tende a se realizar exatamente quando ocorre uma comunicação
ELOISA VIDAL ROSAS Instituto Noos, São Paulo/ $S P$, Brasil 
e um diálogo entre os diferentes níveis e, sobretudo, nos diferentes sentidos; comparando com a transferência psicanalítica, um dos pontos diferentes no conceito desenvolvido por Mony é o papel da história (na transferência psicanalítica há um padrão que se repete, e esta repetição é determinista, não há quase lugar para a mudança, só reconstrução). Na ressonância se põe em ato algo que atravessa os sistemas interconectados (terapêutico, institucional, familiar, cultural) e, como na metáfora musical, uma corda faz vibrar a outra na longitude da onda. Segundo ele, é um conceito sistêmico e circular que insiste na função da experiência de uma pessoa para os membros do sistema humano em que participa.

"Pode-se imaginar a ressonância como um iceberg cuja parte visível sobre a água é semelhante à contratransferência, à ligação entre o passado de uma pessoa e sua experiência em um momento específico. A parte mais importante deste iceberg é a abaixo da linha de flutuação. Representa a função da experiência dessa pessoa como reforço e 'proteção' das construções do mundo, das crenças profundas dos membros do sistema humano ao qual ela pertence; não se trata apenas de proteger as construções do mundo daqueles que o rodeiam, mas também das suas." (Elkaïm, 2010)

Um dos principais efeitos desse conceito é o convite ao terapeuta a se posicionar horizontalmente, numa postura colaborativa, onde a terapia se dá valorizando igualmente as contribuições do(s) cliente(s) e terapeuta(s). Mony trabalha muito com lapsos, atos falhos, conectando histórias e mitos, tão caros à sua cultura de judeu marroquino. Ele olha como um fato singular aparece da mesma forma nos diferentes sistemas (e é aí que a singularidade emerge dessa construção).

O conceito de ressonância se mostra particularmente útil na terapia de casal, assim como nas discussões de histórias clínicas (supervisões). Aplicado ao esquema de Mapa de Mundo e Programa Oficial, é uma ferramenta muito interessante, criando uma possibilidade de compreensão sobre dinâmicas dialógicas recursivas.

Nas palavras de Elkaïm (1990, p. 15): "aquilo que o terapeuta sente remete não somente à sua história pessoal, mas também ao sistema onde emerge esse sentimento: o sentido e a função desse vivido transformam-se em instrumentos de análise e de intervenção a serviço do próprio sistema terapêutico." (Elkaïm, 1990, p 15). Pessoalmente, acredito que um terapeuta se constrói também através das ressonâncias provocadas pelas teorias e técnicas às quais tem acesso. Saul Fuks (1993) usa uma metáfora interessante sobre a utilização das técnicas: "Em sua relação comigo, na qual estamos em um intercâmbio, em que nenhum de nós dois está de fora, o que faço deixa de ser uma técnica, transforma-se numa estratégia de sobrevivência na coordenação social. São usadas porque são parte de mim”... o que fica fora são as 'técnicas' que não foram incorporadas, mas aprendidas como algo para fazer. Aquilo que da minha aprendizagem como terapeuta já se incorporou, me modificou. E, se me modificou, não é a técnica, é parte de mim.

Com o advento do Construcionismo Social alguns avatares da terapia de família foram um pouco deslocados do foco nas formações, o que é lamentável. 
Como se forma um/a terapeuta sem ter conhecido as dinâmicas e processos sugeridos por Virginia Satir? Que escolas e formadores ainda utilizam as metáforas de estética e mudança do genial Bradford Keeney? Carl Whitaker, que jovem estudante de terapia de família o conhece? Fiquei contente ao ver recentemente divulgada a oficina "Conversas focadas na solução", realizada no Instituto Noos em agosto deste ano, onde o ministrante Pedro Martins resgata Steve De Shazer e Insoo Kim Berg e a terapia breve, outra ferramenta pouco valorizada atualmente. A discussão e atualização desses autores são fonte de recursos que alimentam o ofício do terapeuta. As intervenções clássicas se transformam em formas de se posicionar (Harré, 2004) e de participar nas conversações terapêuticas.

A clínica de onde falo tem uma origem sistêmica, e neste momento é fortemente marcada pelas chamadas "terapias pós-modernas" ou "abordagens conversacionais narrativas", baseadas no construcionismo social. A partir destas perspectivas narrativistas, as intervenções clássicas se transformam em formas de se posicionar (Harré, 2004) e de participar nas conversações terapêuticas" (Rosas, 2010). Um corpo teórico/instrumental é encarnado na vida profissional e conceitual de quem a vive (Fuks, 2004).

O artigo muito bem construído e fundamentado por Giovania Mitie Maesima, Monica Barreto e Adriano Beiras chega em muito boa hora, despertando a curiosidade e trazendo para a conversa a utilização desse conceito na prática e na formação. Cumprem a difícil tarefa de condensar um trabalho grandioso em um artigo que explica apropriadamente o conceito; articulam teoria e prática, não só a clínica propriamente dita como a metaclínica, ou seja, a discussão sobre. Os exemplos são interessantes e ilustram adequadamente a teoria. Fico muito curiosa pelos desdobramentos.

Tive a oportunidade de conviver com a personalidade singular de Mony quando, ainda nos tempos do ITF-RJ, o trouxemos para uma apresentação. Figura histriônica nos palcos e na vida, proporcionou-nos momentos divertidos nos bastidores e enriquecedores nas apresentações. Sua contribuição para a Terapia de Família é inestimável. Sua presença está confirmada no próximo congresso da ABRATEF, em 2020. Uma ótima oportunidade para ver o velho e carismático bruxo em ação, oxalá com a performance dos velhos tempos. Vale a pena conferir.

\section{REFERÊNCIAS}

Elkaïm, M. (1990). Se você me ama, não me ame: abordagem sistêmicaem psicoterapia familiar e conjugal. Campinas, SP: Papirus

Elkaïm, M.(2010). À proposduconcept de resonance. In Cahiers critiques de thérapiefamilialeet de pratiques de réseaux (pp. 171-172). Recuperado de https://doi. org/10.3917/ctf.045.0171

Harré, R. (2004). Positioning Theory. Recuperado de http://www.massey.ac.nz/ alock/virtual/welcome.htm
PROCESSO DE FORMAÇÃO

DO TERAPEUTA:

DESCOBRINDO

POTENCIALIDADES

E LIMITAÇÕES NA

PRÁTICA TERAPÊUTICA 
Fuks, S. (2004) "Craftsmanship of contexts": an yet unfinished story of my connection with CMM in Human Systems, vol. 15.

Fuks, S. (1993) Entrevista com SaúlFuks. Entrevista realizada por R. Rapizo. Nova Perspectiva Sistêmica, 2(4), outubro 1993.

Goolishian, H. A. \&Winderman, L. (1989). Contructivismo, autopoieses y sistemas determinados por problemas. Sistemas Familiares, 5(3), 19-29.

Rosas, E. (2010), A construção do estilo do terapeuta: sobre bússolas e GPS em C. Ladvocat (coord.), Psicologia; campo de atuação, teoria e prática. Rio de Janeiro: Booklink.

\section{ELOISA VIDAL ROSAS}

Psicóloga clínica, terapeuta individual, de família e casal, mestra em Comunicação (ECO/UFRJ), facilitadora de processos coletivos. Professora e supervisora em Terapia de Família desde 1987. Membro do corpo docente da Formação em Terapia de Família e Casal do ISBL, Londrina, Paraná, desde 2003. Professora convidada do curso de Formação em Terapia de Família e Casal em Fortaleza, desde 2013. Supervisora e professora do curso de Terapia de Família do Instituto Noos até 2017. Professora convidada do curso Formação em Terapia de Família do Núcleo Contemporâneo, Niterói.

E-mail: eloisa.vidal@gmail.com 